\title{
Processing of Cordierite and Hexacelsian Precursor Powders through Solution-Polymerization Route 溶液一重合を用いたコーディエライト及びヘキサセルシアン前駆体粉末の合成
}

\author{
Sang-Jin LEE \\ Department of Materials Science and Engineering, University of Illinois at Urbana-Champaign, Urbana, Illinois 61801, USA
}

\begin{abstract}
Amorphous-type cordierite $\left(2 \mathrm{MgO} \cdot 2 \mathrm{Al}_{2} \mathrm{O}_{3} \cdot 5 \mathrm{SiO}_{2}\right)$ and hexacelsian $\left(\mathrm{BaO} \cdot \mathrm{Al}_{2} \mathrm{O}_{3} \cdot 2 \mathrm{SiO}_{2}\right)$ precursor powders were prepared by a solution-polymerization route employing a Pechini resin or a PVA solution as a polymeric carrier. After calcination at $800^{\circ} \mathrm{C}$ for $1 \mathrm{~h}$ under atmospheric conditions, the bulky precursors changed into very soft and porous powders. In case of the cordierite precursor prepared using PVA solution, the densification proceeded at lower temperature than in the case of the Pechini resin process. The densification was inhibited by the crystallization of amorphous silica in both cases and it was the reason for the coarse microstructure of the sintered cordierite. Sintered cordierite was closer to pure cordierite with low amount of amorphous-type cordierite phases as was observed in the case of the solution-polymerization route employing PVA solution. Hexacelsian precursor powder, which was prepared by the PVA solution process, was faster crystallized to hexacelsian and showed more sluggish reconstructive transformation behavior than the powder derived from the Pechini resin process.
\end{abstract}

[Received February 2, 1998; Accepted April 17, 1998]

Key-words : Polymeric carrier, Cordierite, Hexacelsian, Solution-polymerization route, Crystallization

1. Introduction

As the requirements of purity and other physical characteristics of ceramic powders become stringent, chemical synthesis methods are becoming more popular over conventional high temperature synthesis routes. It is well known that alkoxy-derived gel powders are very fine and reactive.1),2) However, in multi-component systems such as cordierite ceramics, the difference in hydrolysis rates of each alkoxide caused inhomogeneity in the resultant oxides. ${ }^{3}$ Yoldas ${ }^{4}$ demonstrated that the degree of hydrolysis of alkoxides could be controlled by the hydrolysis temperature, types of catalyst and concentration of alkoxides and water. However, it has been difficult to determine the optimum conditions for hydrolysis.

In 1967, Pechini patented a process ${ }^{5)}$ which was used to fabricate ceramics (e.g., titanates, niobates) for capacitors. It was also suggested to produce a stable and homogeneous oxide powder. ${ }^{6)-9)}$ The process describes utilization of citric acid in combination with polyethylene glycol to form a resin through condensation reactions. The acid acts as a chelating agent which chemically binds the cations that are dissolved in the solution. The polymerization is based on the polyesterification between the metal-chelate complexes and polyhydroxyl alcohols. Due to the chelating action of the hydroxy carboxylic acids and the polymeric network, the cations have low mobility, so that precipitation is hindered. The result is ceramic powders with better chemical homogeneity and smaller particle size.

In this work, the crystallization and densification behavior of fine and homogeneous three-component oxide ceramic powders prepared by a solution-polymerization route were studied. A rather simple-structured and inexpensive polymer, PVA, was used as the polymeric carrier and the results were compared with the results obtained from the Pechini resin process. There are two general categories of PVA, fully and partially hydrolyzed. Fully hydrolyzed PVA has a $98 \%$ degree of hydrolysis or higher. Partially hydrolyzed is below 98\%. The properties of polyvinyl alcohol depend on its degree of polymerization, degree of hydrolysis, and distribution of the degree of hydrolysis. ${ }^{10)}$ The solubility of polyvinyl alcohol in water depends on the degree of hydrolysis and degree of polymerization. The hydroxyl groups hinder the solubility due to strong hydrogen bonding between the intra- and intermolecular $\mathrm{OH}$ groups. The intra and intermolecular bonding can be reduced if there are residual acetate groups which are hydrophilic. The aim of this study is to present a synthesis process in which chelation is not necessary for a stable precursor ceramics. Cordierite $\left(2 \mathrm{MgO} \cdot 2 \mathrm{Al}_{2} \mathrm{O}_{3} \cdot 5 \mathrm{SiO}_{2}\right)$ and hexacelsian $\left(\mathrm{BaO} \cdot \mathrm{Al}_{2} \mathrm{O}_{3} \cdot 2 \mathrm{SiO}_{2}\right)$ powders were synthesized and characterized as the examples.

\section{Experimental}

2.1 Powder preparation and sintering

The cordierite powder was synthesized from $\mathrm{Mg}\left(\mathrm{NO}_{3}\right)_{2}$. $6 \mathrm{H}_{2} \mathrm{O}$ (reagent grade, Aldrich Chemical Co., Milwaukee, $\mathrm{WI}$ ); $\mathrm{Al}\left(\mathrm{NO}_{3}\right)_{3} \cdot 9 \mathrm{H}_{2} \mathrm{O}$ (reagent grade, Aldrich Chemical Co., Milwaukee, WI) and Ludox AS-40 Colloidal silica (40 mass\% suspension in water, Du Pont Chemicals, Wilmington, $\mathrm{DE})$. For the hexacelsian powder, $\mathrm{Ba}\left(\mathrm{NO}_{3}\right)_{2}$ (reagent grade, Aldrich Chemical Co., Milwaukee, WI); Al $\left(\mathrm{NO}_{3}\right)_{3} \cdot 9 \mathrm{H}_{2} \mathrm{O}$ (reagent grade, Aldrich Chemical Co., Milwaukee, WI) and Ludox AS-40 Colloidal silica (40 mass\% suspension in water, Du Pont Chemicals, Wilmington, DE) were used. For each precursor, the nitrate salts and the colloidal silica were dissolved in deionized water in stoichiometric proportions. As an organic carrier, either the Pechini resin or the PVA solution was added to the mixture. The 85 mass $\%$ or 60 mass $\%$ Pechini resins, ${ }^{8), 11)}$ which consisted of $50 \mathrm{~mol} \%$ citric acid monohydrate (Fisher Chemical, Fair Lawn, NJ) and $50 \mathrm{~mol} \%$ ethylene glycol (Fisher Chemical, Fair Lawn, NJ), were used in this process. The PVA solution was made from 5 mass \% polyvinyl alcohol $\left(-\left[\mathrm{CH}_{2} \mathrm{CHOH}\right]_{n}-\right.$ or PVA, with a degree of polymerization-1700, Air Products and Chemicals, Inc., Allentown, PA) dissolved in water. The amount of the PVA to cation sources in the solution was adjusted in such a way that there were 4 times more positively charged valences of cations than the negatively charged functional ends of the organics. ${ }^{12), 13)}$ The resulting solutions were heated and stirred until a crisp, aerated gel was formed. The gel was ground and calcined under an air atmosphere at $800^{\circ} \mathrm{C}$ for 1h. The calcined powders were ball milled with zirconia media for $12 \mathrm{~h}$. Iso-propyl alcohol was used as a solvent for milling. The ball-milled powders were uniaxially pressed at $20 \mathrm{MPa}$ followed by iso-static pressing at $170 \mathrm{MPa}$ for 10 
min. The pellet-shaped green compacts were sintered in an air atmosphere. In every cases the furnace was cooled down to room temperature.

\subsection{Characterization}

The particle size distribution and specific surface area of the calcined and ball-milled powders were studied by an Xray absorption spectrometry (Sedigraph Model 5000E, Micromeritics) and nitrogen gas absorption (Model ASAP 2400, Micromeritics, Norcross, GA) method. The powders for particle size distribution were suspended in a calibrated dispersion liquid. The suspensions were ultrasonicated for 3 min before analysis. The development of crystalline phases as a function of heating temperature was studied using a Rigaku spectrometer (DMax automated powder diffractometer, Rigaku/USA, Danvers, MA) with $\mathrm{Cu} \mathrm{K} \alpha$ radiation $(40 \mathrm{kV}, 40 \mathrm{~mA})$. The heating rate was $5^{\circ} \mathrm{C} / \mathrm{min}$ and the samples had a holding time for $2 \mathrm{~h}$ at each temperature. The density of the sintered specimens was estimated by the Archimedes' method using distilled water as a displacement liquid. The relative density was calculated using the density of the $\alpha$-cordierite $\left(2.51 \mathrm{~g} / \mathrm{cm}^{3}\right)$ and of the hexacelsian $\left(3.30 \mathrm{~g} / \mathrm{cm}^{3}\right)$ as the theoretical density. The thermal expansion coefficient of the sintered cordierite specimens was determined using a dilatometer (Netzsch Dilatometer, $402 \mathrm{E}$, Germany) up to $1100^{\circ} \mathrm{C}$ at a heating rate of $5^{\circ} \mathrm{C} / \mathrm{min}$. Linear shrinkage behavior was measured by determining the dimensions with Vernier callipers at each temperature. To determine the residual carbon content in the calcined powders, the chemical compositions were analyzed using an inductively coupled plasma emission spectroscopy (Plasma II, Perkin-Elmer, Norwalk, CT). The microstructures of sintered specimens were examined by scanning electron microscopy, SEM (ISI DS-130, International Scientific Instruments, Santa Clara, CA).

\subsection{Cordierite}

\section{Results}

Both precursors, which were prepared with Pechini resin or PVA solution, were very soft and porous. Fine powders were obtained by just hand grinding the precursors for a few minutes. Figure 1 shows particle size distributions of the calcined powders derived from different organic carrier. The powder derived from the Pechini resin (85\% resin content) had a narrower particle size distribution than that of $60 \%$ resin content with particle sizes ranging from $3 \mu \mathrm{m}$ to $50 \mu \mathrm{m}$. In the case of the powder derived from PVA solution, it showed finer powder with particle sizes ranging from $0.2 \mu \mathrm{m}$ to $10 \mu \mathrm{m}$.

Figure 2 shows variations of phases for amorphous cordierite, derived from Pechini resin, as a function of heating temperature. Crystalline spinel phase appeared at $900^{\circ} \mathrm{C}$ and persisted till $1250^{\circ} \mathrm{C}$. On the other hand, silica remained amorphous up to $1150^{\circ} \mathrm{C}$. As temperature further increased to $1200^{\circ} \mathrm{C}$, amorphous silica crystallized to quartz. $\alpha$-cordierite started to form at $1250^{\circ} \mathrm{C}$ by the solid-state reaction between quartz, cristobalite and spinel. The $\alpha$-cordierite was formed without a sequential formation of crystalline cordierite (amorphous $\rightarrow \mu \rightarrow \alpha$ ). All phases turned to $\alpha$-cordierite at $1350^{\circ} \mathrm{C}$.

In comparison, the X-ray diffraction spectra of amorphous cordierite derived from PVA solution are shown in Fig. 3. The precursor remained amorphous at $900^{\circ} \mathrm{C}$. However, in contrast to the Pechini resin process, $\mu$-cordierite appeared with crystalline spinel at $1000^{\circ} \mathrm{C}$. The $\mu$-cordierite was detected below $1200^{\circ} \mathrm{C}$ and coexisted with $\alpha$-cordieirte at a temperature ranging from $1100^{\circ} \mathrm{C}$ to $1200^{\circ} \mathrm{C}$. The $\mu$-cordierite can be decomposed into $\beta$-quart $z$ solid solution at $1100^{\circ} \mathrm{C} .{ }^{14), 15)}$ However, it was very difficult to distinguish $\beta$-quartz solid solution from $\mu$-cordierite because the peaks have almost same Bragg angle. As the temperature increased to $1200^{\circ} \mathrm{C}, \mu$-cordierite phase transformed to $\alpha$-cordieirte. The onset temperature of $\alpha$-cordieriet was lower than the Pechini resin process. Only $\alpha$-cor-
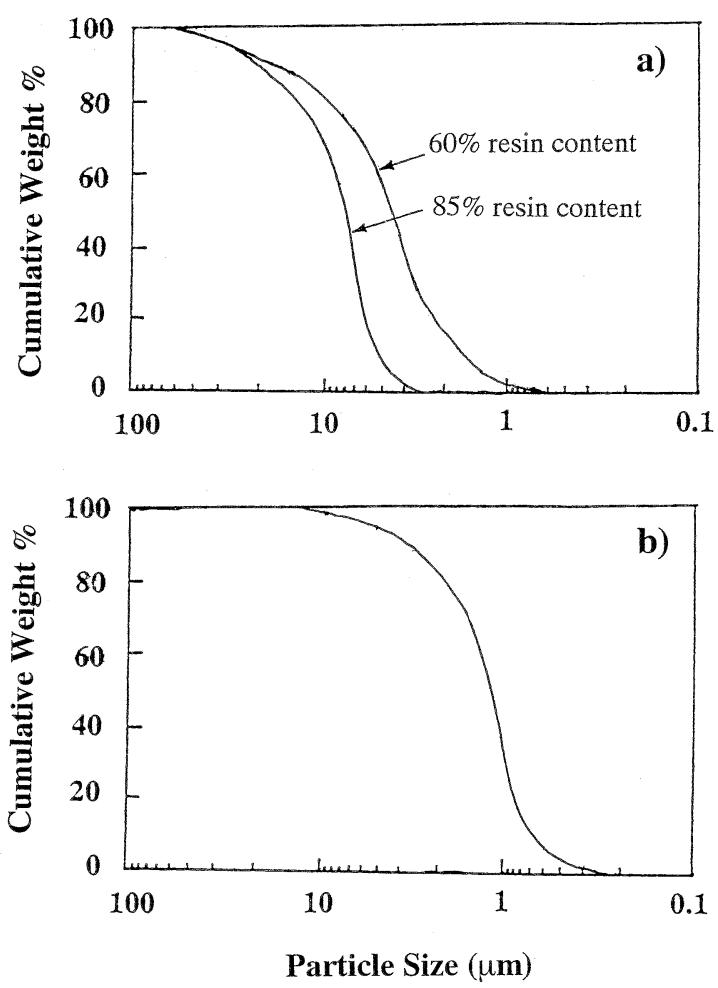

Fig. 1. Effect of organic carrier on the particle size distributions of the calcined cordierite powders derived from (a) Pechini resin and (b) PVA solution.

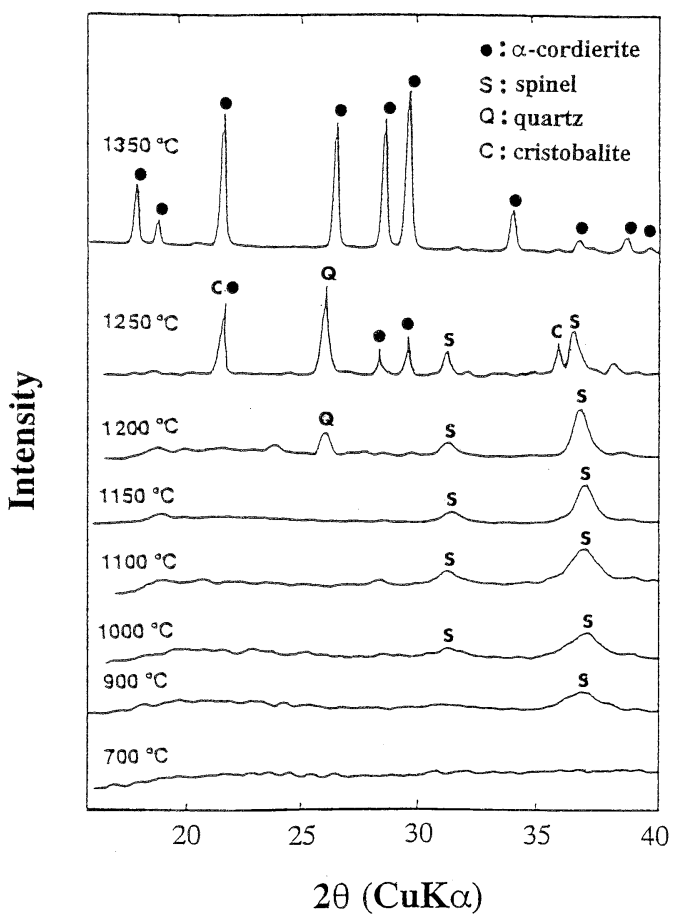

Fig. 2. X-ray diffraction spectra of amorphous cordierite derived from Pechini resin at various heating temperatures (holding time at each temp.: $2 \mathrm{~h}$ ). 


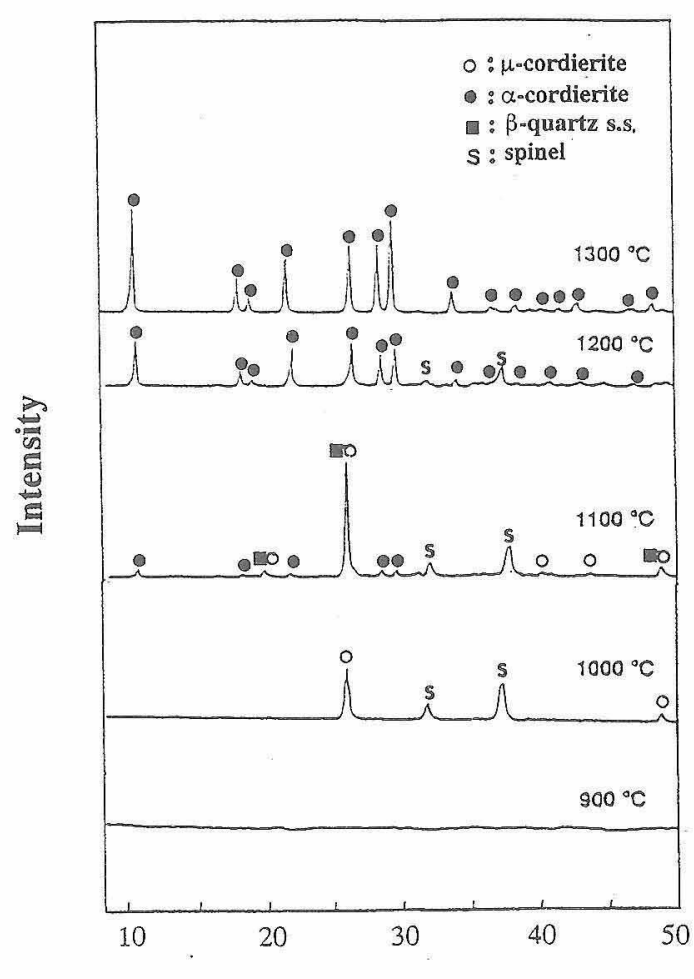

$2 \theta(\mathbb{C u K} \alpha)$

Fig. 3. X-ray diffraction spectra of amorphous cordierite derived from PVA solution at various heating temperatures (holding time at each temp.: $2 h$ ).

dierite remained at $1300^{\circ} \mathrm{C}$.

Figure 4 shows the linear shrinkage of amorphous-type cordierite powder compacts as a function of sintering temperature. The powders were not ball-milled after calcination. The cordierite compact prepared with the PVA solution densified between $700^{\circ} \mathrm{C}$ and $1000^{\circ} \mathrm{C}$. However, the densification stopped at the temperature of crystallization of $\mu$-cordierite. At temperatures above $1200^{\circ} \mathrm{C}$, the powder compact continued to swell slightly. On the other hand, the densification of the powder compact prepared with the Pechini resin was not affected by the crystallization of spinel phase. These results indicate that the densification, in both cases, stops at the crystallization point of amorphous silica. The powder compact derived from the Pechini

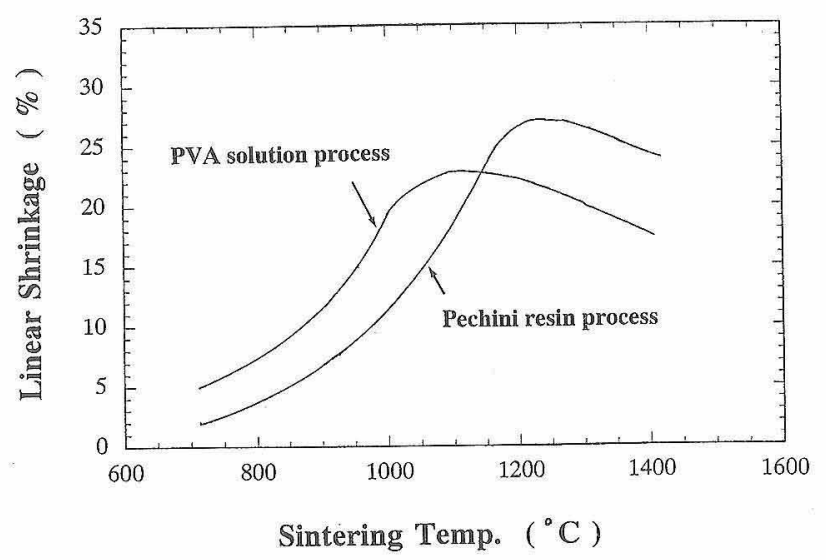

Fig. 4. Linear shrinkage of as calcined, compacted amorphous cordierite powder prepared with Pechini resin and PVA solution as a function of sintering temperature. resin also showed a little swelling above $1300^{\circ} \mathrm{C}$.

Figure 5 shows variations of bulk densities for as calcined cordierite powder compacts at different sintering temperature. The bulk density of sintered specimen derived from PVA solution had a maximum value at $1100^{\circ} \mathrm{C}$. The bulk density was higher than the true density of $\alpha$-cordierite in the temperature range from $1000^{\circ} \mathrm{C}$ to $1200^{\circ} \mathrm{C}$, because $\mu$ cordierite and spinel, whose density is $3.59 \mathrm{~g} / \mathrm{cm}^{3},{ }^{16)}$ phase were the matrix phases of the sintered body. The reduction in density above $1100^{\circ} \mathrm{C}$, which is related to the swelling (Fig. 4), can be ascribed to the formation of $\alpha$-cordierite. In the case of the powder compact derived from Pechini resin route, the maximum density was obtained at $1250^{\circ} \mathrm{C}$ and

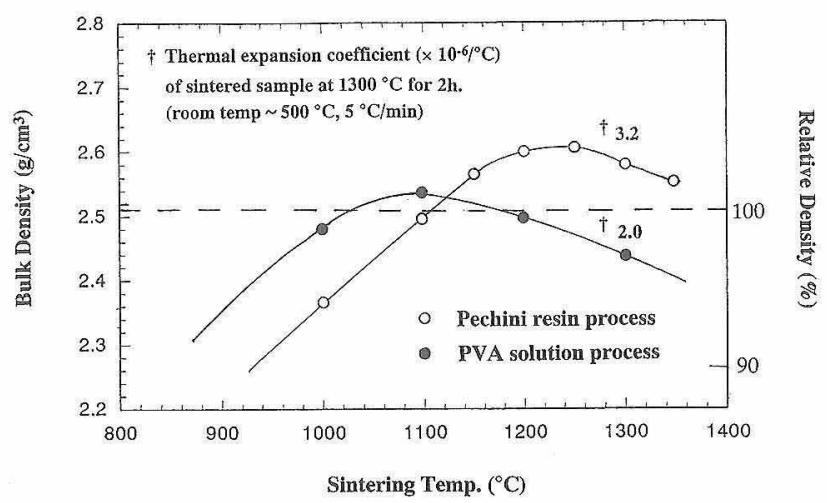

Fig. 5. Bulk densities of the as calcined amorphous-type cordierite powder compacts sintered at various temperatures for $2 \mathrm{~h}$.
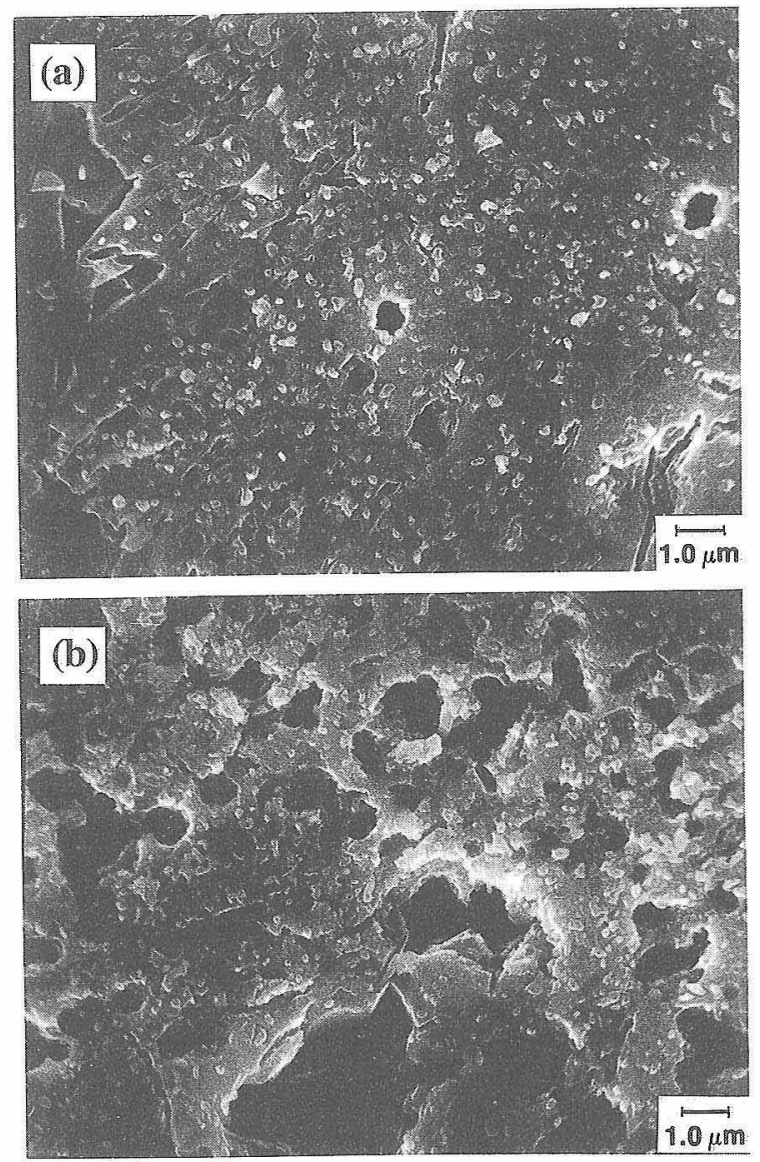

Fig. 6. SEM photographs of polished surface of sintered cordierite specimens (un-ball milled) derived from (a) Pechini resin and (b) PVA solution sintered at $1300^{\circ} \mathrm{C}$ for $2 \mathrm{~h}$. 
then the reduction in density occurred due to the formation of $\alpha$-cordierite. The higher bulk density, than the true density of $\alpha$-cordierite at above $1100^{\circ} \mathrm{C}$, is attributed to the spinel, quartz and cordierite-type glass phases in the matrix. Even though only $\alpha$-cordierite was detected in the sintered body by X-ray diffraction at $1350^{\circ} \mathrm{C}$ (Fig. 2), the density was higher than true density of $\alpha$-cordierite. This indicates that the cordierite-type glass phases still remained in the matrix after densification. $\left.{ }^{2}\right)$ Moreover, the thermal expansion coefficient $\left(3.2 \times 10^{-6} /{ }^{\circ} \mathrm{C}\right)$ of the sintered specimen was higher than that of pure $\alpha$-cordierite. This result confirmed the fact that the sintered body did not consist of only $\alpha$-cordierite but also some cordierite-type glassy phases. In contrast, the closer match of the thermal expansion coefficient $\left(2.0 \times 10^{-6} /{ }^{\circ} \mathrm{C}\right)$ of the sintered specimen, prepared with PVA solution, indicates that the sintered specimen was relatively pure. The low thermal expansion coefficient meant that most of the $\mu$-cordierite and the other phases changed into $\alpha$-cordierite through transformation and solid state reaction above $1100^{\circ} \mathrm{C}$.

The observed densification behavior reflected that the main sintering mechanism was by viscous-flow sintering of the cordierite-type glass phases in both cases. In the PVA solution process, the viscous-flow sintering stopped at the temperature at which amorphous silica crystallized to $\mu$-cordierite. In the case of the Pechini resin process, however, the densification by viscous-flow lasted longer than the powder compact prepared with PVA solution due to the residual cordierite-type glass. This is the reason for the enhanced densification observed in the Pechini resin process.

The scanning electron micrographs of the sintered cordierite specimens are shown in Fig. 6. These microstruc-

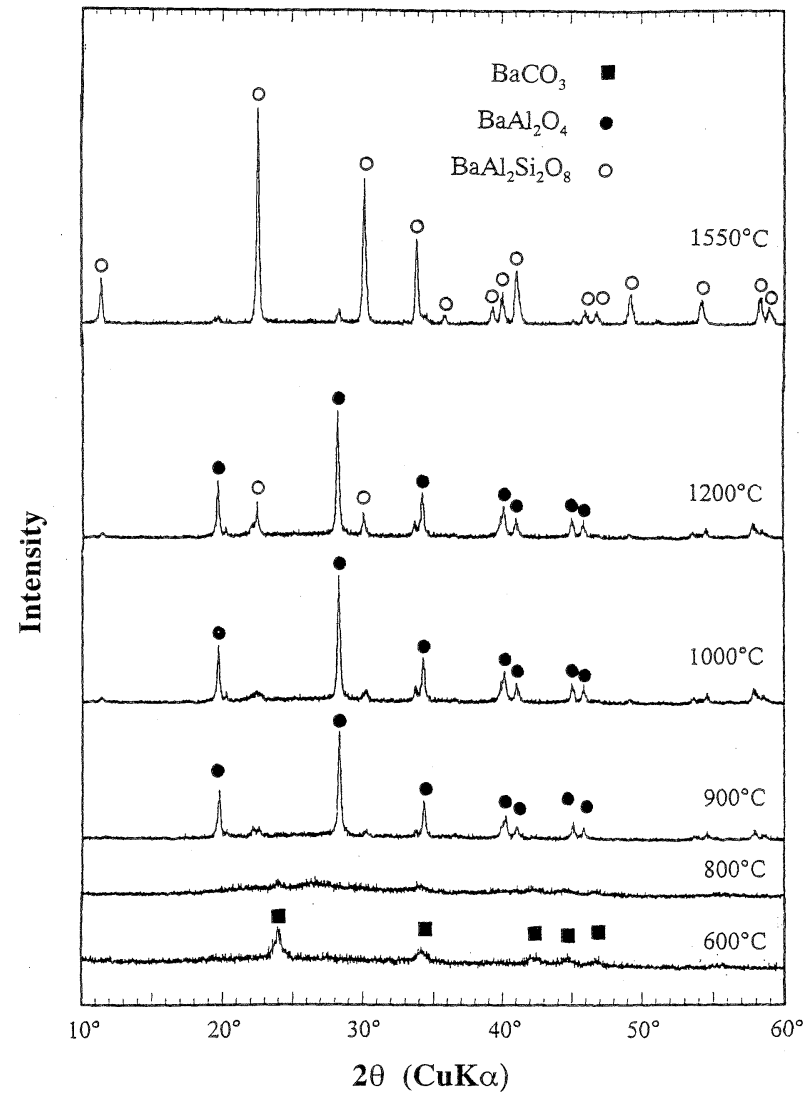

Fig. 7. X-ray diffraction patterns of amorphous-type hexacelsian powder derived from Pechini resin as a function of heating temperature. Holding time at each temperature was $2 \mathrm{~h}$. tures were obtained from as-calcined powders prior to ball milling. The micrograph of the sintered specimen derived from the Pechini resin was more dense than that from the PVA solution process. The circular-type pores confirmed that viscous-flow sintering had occurred. On the other hand, the sintered specimen derived from PVA solution retained some large pores after viscous sintering. This was because the amorphous silica was depleted by crystallization of $\mu$ cordierite before full viscous-flow sintering occurred. The formation of $\mu$-cordierite at around $1000^{\circ} \mathrm{C}$ also occurred in the sol-gel powder preparation process. ${ }^{1,17)}$ This means that the PVA solution process is a more atomistically homogeneous synthesis method in comparison with the Pechini resin process.

\subsection{Hexacelsian}

The development of crystalline phases from the precursors during calcination are shown in Figs. 7 and 8. For the precursor made using solution-polymerization route, $\mathrm{BaCO}_{3}$ was observed to crystallize at low temperatures presumably during pyrolysis. With subsequent heating the $\mathrm{BaCO}_{3}$ decomposed and the resultant $\mathrm{Ba}^{2+}$ ions were redissolved into the amorphous oxide. Between $900^{\circ} \mathrm{C}$ and $1000^{\circ} \mathrm{C}$ another intermediate phase, $\mathrm{BaAl}_{2} \mathrm{O}_{4}$, was observed to crystallize along with hexacelsian. With additional heating the $\mathrm{BaAl}_{2} \mathrm{O}_{4}$ phase reacted with the $\mathrm{SiO}_{2}$ in the system to form hexacelsian. The crystallization of the $\mathrm{BaAl}_{2} \mathrm{O}_{4}$ intermediate was much more extensive in the powder derived from Pechini resin process. The crystallization of hexacelsian was detected at lower temperatures in the powder made from PVA solution process.

Figures 9 and 10 show X-ray diffraction profiles for hexacelsian powder annealed at $1600^{\circ} \mathrm{C}$ as a function of annealing time. Hexacelsian $\rightarrow$ celsian reconstructive transforma-

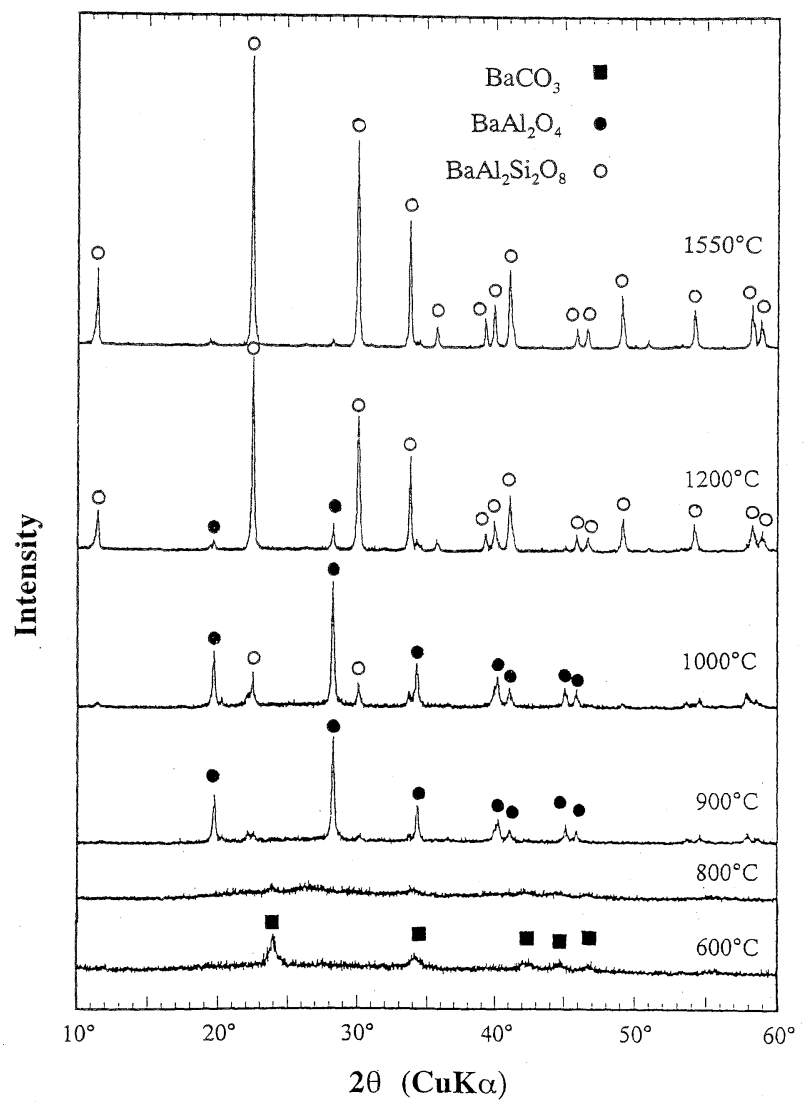

Fig. 8. X-ray diffraction patterns of amorphous-type hexacelsian powder derived from PVA solution as a function of heating temperature. Holding time at each temperature was $2 \mathrm{~h}$. 


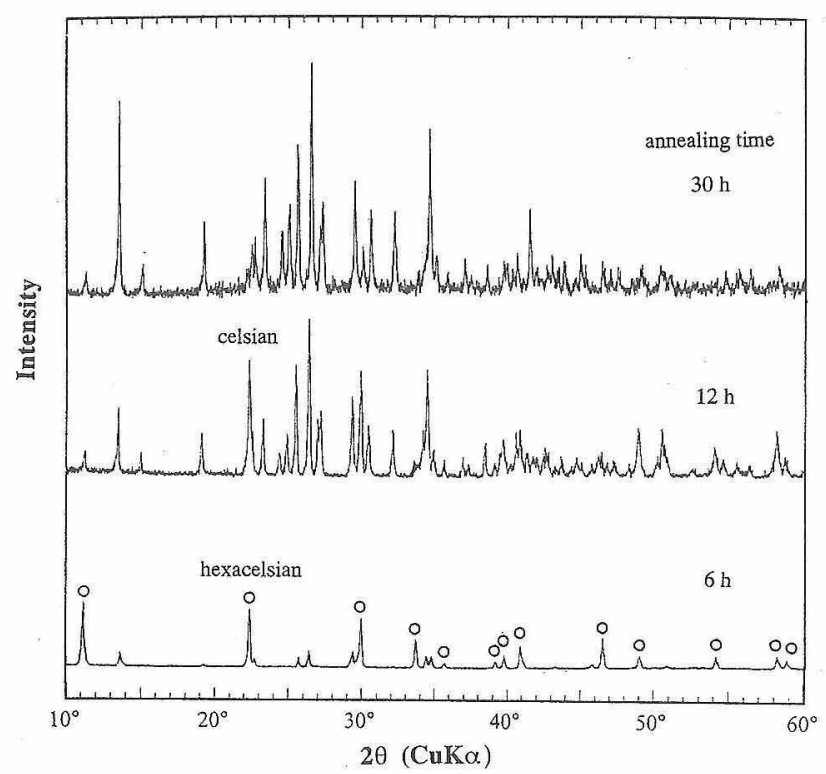

Fig. 9. X-ray diffraction profiles for hexacelsian powder prepared with Pechini resin as a function of annealing time (annealing at $\left.1600^{\circ} \mathrm{C}\right)$.

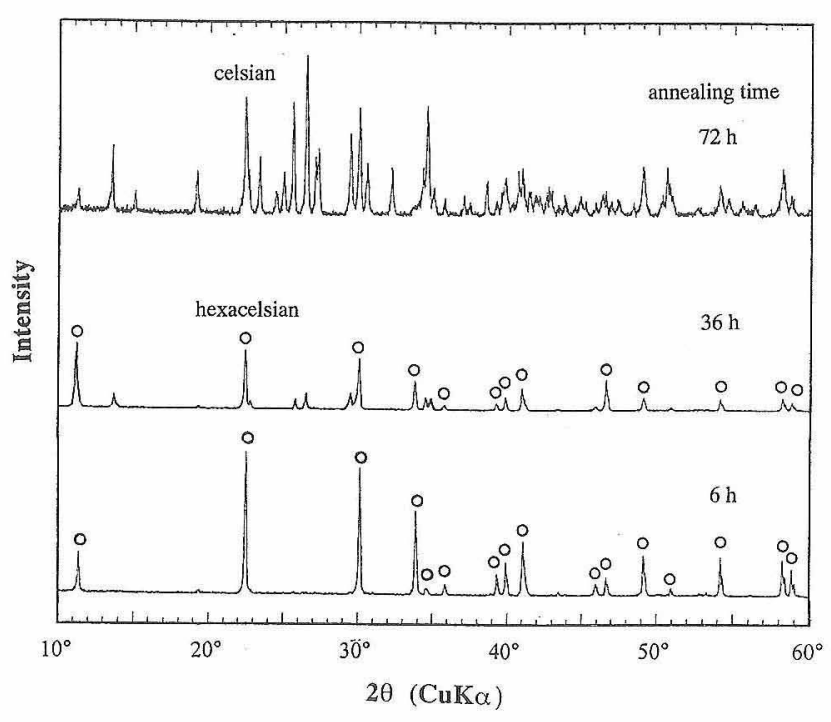

Fig. 10. X-ray diffraction profiles for hexacelsian powder prepared with PVA solution as a function of annealing time (annealing at $\left.1600^{\circ} \mathrm{C}\right)$.

tion $^{18)}$ was examined in both cases. It is known that the equilibrium $(\gamma)$ structure exist above $1590^{\circ} \mathrm{C}$ when it converts to the celsian structure by a slow, sluggish, reconstructive transformation mechanism. With increasing annealing time, celsian phase increased gradually while hexacelsian phase decreased. In the case of the powder derived from Pechini resin, the transformation occurred at much shorter annealing time. The easier reconstructive transformation had observed in $\mathrm{Al}_{2} \mathrm{O}_{3}$ doping hexacelsian or celsian glass ceramics including hexacelsian-type glass phase. ${ }^{19)}$ This result suggests amorphous phase exists in the hexacelsian powder made using Pechini resin process.

\subsection{Densification}

PVA solution process showed more stable and relatively homogeneous reaction in solution-polymerization route than the Pechini resin process. However, in the case of cordierite, the sintered density did not reach the full density
Table 1. Powder Analysis Data and Sintered Relative Density of Calcined and Ball-Milled Cordierite and Hexacelsian Powders Derived from PVA Solution

\begin{tabular}{ccccc}
\hline $\begin{array}{c}\text { Oxide } \\
\text { ceramics }\end{array}$ & $\begin{array}{c}\text { Average particle } \\
\text { size } \\
(\mu \mathrm{m})\end{array}$ & $\begin{array}{c}\text { Residual } \\
\text { carbon } \\
(\text { wt } \%)\end{array}$ & $\begin{array}{c}{ }^{\dagger} \text { Specific surface } \\
\text { area } \\
\left(\mathrm{m}^{2} / \mathrm{g}\right)\end{array}$ & $\begin{array}{c}\text { इRelative } \\
\text { density } \\
(\%)\end{array}$ \\
\hline Cordierite & 0.3 & 0.07 & 80 & 97.9 \\
Hexacelsian & 0.8 & 0.09 & 63 & 97.5 \\
\hline
\end{tabular}

${ }^{\dagger}$ Specific surface area of as calcined powder ; cordierite : $37 \mathrm{~m}^{2} / \mathrm{g}$, hexacelsian : $22 \mathrm{~m}^{2} / \mathrm{g}$. ${ }^{3}$ Measured with polycrystalline cordierite sintered at $1300{ }^{\circ} \mathrm{C}$ for $2 \mathrm{~h}$ and polycrystalline hexacelsian sintered at $1550{ }^{\circ} \mathrm{C}$ for $2 \mathrm{~h}$.
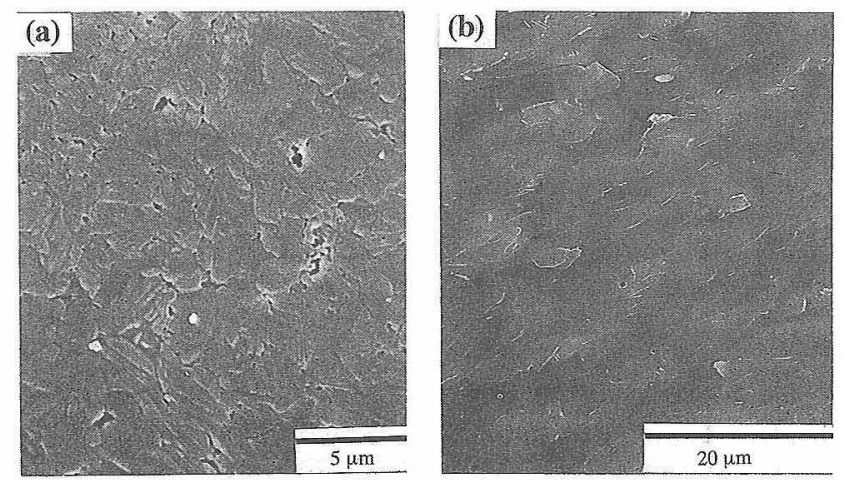

Fig. 11. Microstructures of the densified specimens (ball-milled) for (a) polished and chemical etched surface of $\alpha$-cordierite and (b) fracture surface of hexacelsian.

value because of the crystallization of silica phase at an early stage of the viscous flow sintering. If enough densification occurs before the crystallization of the amorphous silica begins, it is possible to prepare dense oxide ceramics through the PVA solution process. Hence, it is necessary to obtain a fine powder, which can enable near full densification at an early sintering stage, for producing a dense pellet from the solution-polymerization route.

The ball-milled powders in the PVA solution process showed submicron particle size and high sinterability. The powder analysis data and densification behavior of the ballmilled powders are listed in Table 1. Ball-milled powders had submicron particle size showing high specific surface area. The ball milling was effective on the soft and porous, amorphous-type calcined powder. In both cases, infinitesimal residual carbon (below 0.1 mass\%) was detected in the ball-milled powders. This means that the polymeric carriers burnt out almost completely during the calcination process. After sintering, the ball-milled powder compacts showed above $97 \%$ relative density. The densified microstructures of $\alpha$-cordierite and hexacelsian were shown in Fig. 11.

\section{Discussion}

In the Pechini resin process, free silica remained even after crystallization and resulted in amorphous phases in the crystallized matrix. These results mean that chelation of the dissolved metal ions by the carboxylic acid end of the citric acid was incomplete in this process. The chelating reaction is suggested to be responsible for the formation of a stable, relatively homogeneous pre-ceramic organometallic precursor. On the other hand, the stabilization of the metal ions on the chelation route by the Pechini resin was not enough in the multi-component system. 
In the case of the cordierite powder by PVA solution method, the formation of $\mu$-phase reduced the chances of forming other silicate compounds, such as spinel and cristobalite, or the residual cordierite-type amorphous phase.1),4) It can be done by homogeneous distribution of metal cations on atomistic scale during the process. The large chain molecule of PVA, which included hydroxyl functional groups, dispersed the metal ions homogeneously by steric entrapment and polymerization mechanism. In the PVA solution process, a homogeneously mixed solution was obtained easily by the completely dissolving colloidal silica without any adjustment of the solution $\mathrm{pH}$, in comparison with the mixed colloidal processing route. ${ }^{4), 20)}$

\section{Conclusions}

A PVA solution process was a simple and useful technique for producing multi-component systems. Relatively dense and pure $\alpha$-cordierite and hexacelsian polycrystalline oxide ceramics were obtained by densification of submicron-size, amorphous-type powders made by the PVA solution-polymerization route. A very soft and porous calcined powder, which can be ball milled to submicron particles, was made after burning out the PVA polymeric carrier. The homogeneous mixing process and the steric entrapment mechanism by large chain molecules of PVA resulted in a homogeneous and stable precursor powder.

\section{References}

1) H. Suzuki, K. Ota and H. Saito, Yogyo-Kyokai-Shi, 95, 28-31 (1987).
2) H. Suzuki, K. Ota and H. Saito, Yogyo-Kyokai-Shi, 95, 32-37 (1987).

3) T. Hayashi and H. Saito, J. Mater. Sci., 15, 1971-77 (1980).

4) B. E. Yoldas, J. Non-Cryst. Solids, 63, 145-54 (1984).

5) M. P. Pechini, U.S. Patent No. 3,330,697, U.S. Patent Office (1967).

6) D. Budd and D. A. Payne, Mater. Res. Soc. Symp. Proc., 32, (1984) p. 239.

7) L. W. Tai and P. A. Lessing, J. Mater. Res., 7, 502-10 (1992).

8) L. W. Tai and P. A. Lessing, J. Mater. Res., 7, 511-19 (1992).

9) P. A. Lessing, Am. Ceram. Soc. Bull., 68, 1002-07 (1989).

10) C. A. Finch, "Polyvinyl Alcohol: Properties and Applications," John Wiley \& Sons, London (1973) p. 17.

11) M. A. Gülgün, O. O. Popoola and W. M. Kriven, J. Am. Ceram. Soc., 77, 531-39 (1994).

12) M. A. Gülgün and W. M. Kriven, "Ceramic Transactions, Vol. 62," Ed. by J. J. Kingsley, C. H. Schilling and J. H. Adair, Am. Ceram. Soc., Westerville, OH (1996) pp. 57-66.

13) M. A. Gülgün, M. H. Nguyen and W. M. Kriven, J. Am. Ceram. Soc., accepted in (1998).

14) H. Y. Jang and B. C. Lim, J. Mater. Res., 9, 2627-33 (1994).

15) W. Schreyer and J. F. Schairer, Z. Kristallogr., 116, 60 (1961).

16) “Ceramic Source, Vol. 7," Am. Ceram. Soc., Westerville, OH (1991) p. 345

17) J. Werckmann, P. Humbert, C. Esnouf, J. C. Broudic and S. Vilminot, J. Mater. Sci., 28, 5229-36 (1993).

18) S. J. Lee and Y. S. Yoon, J. Kor. Assoc. Cryst. Growth, 7, 42836 (1997).

19) L. Barbieri, A. B. Corradi, C. Leonelli, T. Manfredini and C. Siligardi, Mater. Res. Bull., 30, 27 (1995).

20) B. C. Lim and H. M. Jang, J. Am. Ceram. Soc., 76, 1482-90 (1993). 